\title{
Gender differences in pulmonary arterial hypertension patients with BMPR2 mutation: a meta-analysis
}

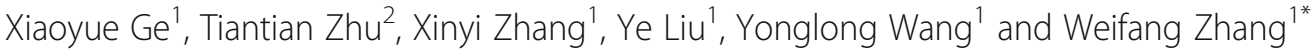

\begin{abstract}
Objective: To investigate the differences in the proportions of BMPR2 mutations in familial hereditary pulmonary arterial hypertension (HPAH) and idiopathic pulmonary arterial hypertension (IPAH) between males and females and the relationship between BMPR2 mutation and PAH severity.

Methods: A computer was used to search the electronic Cochrane Library, PubMed/MEDLINE, and EMBASE databases for clinical trials containing information on the relationship between PAH prognosis and BMPR2 mutations through March 2019. After obtaining the data, a meta-analysis was performed using Review Manager Version 5.3 and Stata.

Results: A meta-analysis was performed on 17 clinical trials (2198 total patients: 644 male, 1554 female). The results showed that among patients with HPAH and IPAH, the BMPR2 mutation rate is higher in male than in female patients [male group (224/644, 34.78\%), female group (457/1554, 29.41\%), OR=1.30, 95\% Cl: 1.06 1.60, $P=0.01, \mathrm{I}^{2}=10 \%$ ]. Furthermore, haemodynamic and functional parameters were more severe in IPAH and HPAH patients with BMPR2 mutations than in those without, and those with BMPR2 mutation were diagnosed at a younger age. The risk of death or transplantation was higher in PAH patients with BMPR2 mutations than in those without $(\mathrm{OR}=2.51,95 \%$ $\left.\mathrm{Cl}: 1.29 \sim 3.57, P=0.003, \mathrm{I}^{2}=24 \%\right)$. Furthermore, the difference was significant only in male patients ( $\mathrm{OR}=5.58$, 95\% Cl: $2.16 \sim 14.39, P=0.0004, I^{2}=0 \%$ ) and not in female patients ( $\mathrm{OR}=1.41,95 \% \mathrm{Cl}: 0.75 \sim 2.67, P=0.29, \mathrm{I}^{2}=0 \%$ ).
\end{abstract}

Conclusion: Among patients with HPAH and IPAH, men are more likely to have BMPR2 mutations, which may predict more severe PAH indications and prognosis.

Keywords: BMPR2 mutations, Pulmonary arterial hypertension, Gender, Meta-analysis

\section{Backgrounds}

Pulmonary arterial hypertension (PAH) refers to the first subgroup of pulmonary hypertension $(\mathrm{PH})$ patients, which is defined as a pulmonary arterial wedge pressure $(\mathrm{PAWP}) \leq 15 \mathrm{mmHg}$ and an indexed pulmonary vascular resistance (PVRI) greater than 3 Wood units [1]. Although the use of targeted drugs (such as endothelin receptor antagonists, prostacyclin inhibitors, etc.) has increased the survival rate of $\mathrm{PAH}$ patients and significant improvements in PAH outcome have been realized in the modern era (median survival 7 years) compared to the National Institutes of Health registry from the early 1980s (median

\footnotetext{
*Correspondence: z_weifang@163.com

'Department of Pharmacy, The Second Affiliated Hospital of Nanchang University, Nanchang 330006, China

Full list of author information is available at the end of the article
}

survival 2.8 years) [2], its long-term prognosis remains poor. The aetiology of PAH involves environmental and genetic factors, and its pathogenesis is complex and has not been fully elucidated to date..

Bone morphogenetic protein (BMP), a multifunctional protein, was originally identified as an osteoinductive component in extracts derived from bone. BMPs play important roles through BMP receptors (BMPRs) in a multitude of processes during embryonic development and adult homeostasis. BMPRs are serine/threonine kinase receptors composing an intracellular serine/threonine kinase domain, a single transmembrane domain, and a short extracellular domain containing 10-12 cysteine residues. The BMP type II receptor (BMPRII), activin type II receptor (ActRII), and activin type IIB receptor (ActRIIB) are three type II BMPRs present in 
mammals. Autosomal dominant mutation causing haploinsufficiency or loss of function of BMPR2 is the most common cause of PAH. Studies have reported more than 298 BMPR2 mutations are responsible for 55 to $70 \%$ of heritable PAH (HPAH) and 11 to $40 \%$ of idiopathic PAH (IPAH) [3]. What's more, the BMPR2 signaling pathway is also impaired in $\mathrm{PAH}$ patients without BMPR2 mutations [4]. Despite the impact of BMPR2 as the main genetic factor for $\mathrm{PAH}$, currently, our understanding of the specific mechanisms of BMPR2 in PAH is incomplete. Unravelling these uncertainties may be could explain why only $20 \%$ of BMPR 2 mutation carriers develop advanced PAH [5] and might predict which mutation carriers will further develop PAH. It is now recommended by the European guidelines for the management of $\mathrm{PAH}$ that patients recently diagnosed with idiopathic, heritable, or anorexigen-associated $\mathrm{PAH}$ should be offered genetic counselling and screening for BMPR2 mutations, mainly to enable predictive genetic testing of relatives. Studies have suggested that patients with PAH who carry causal BMPR2 mutations may present at an earlier age and have more severe haemodynamic compromise [6]. Additionally, there is a "sex paradox" exists in PAH while women are more likely than men to develop PAH, men have worse outcomes than those observed in their opposite sex counterparts [7]. Therefore, among PAH patients, the question of whether there is a gender difference in BMPR2 mutation is still unclear. In this article, we sought to combine recent clinical research investigating BMPR2 and PAH to present an evidence-based meta-analysis and explain the scientific phenomenon of gender differences in the development of $\mathrm{PAH}$ disease. Moreover, these data provide clinical guidance for the treatment of gender-based differences in PAH.

\section{Methods}

\section{Literature search}

We obtained individual participant data from studies identified through systematic searches of the published literature performed using the Cochrane Library, PubMed/MEDLINE, and EMBASE databases (the following search terms were used: "BMPR2 or bone morphogenetic protein receptor type 2" and "pulmonary hypertension") up to March 2019. The electronic searches were specifically performed to obtain articles in peer-reviewed journals. Additional data not identified in the electronic databases, especially original data that were absent from published articles, were collected from other data resources. We also performed an additional search of the references of the retrieved studies. Specifically, we contacted the corresponding authors to obtain original data that were not reported in the identified published articles.

\section{Selection of studies for inclusion in the review}

Cohort studies were included if they met the following criteria: 1) Type of study: retrospective or prospective; 2 ) Types of participants: idiopathic PAH or heritable PAH with a date of PAH diagnosis defined as the date of diagnostic right heart catheterization; 3) Type of interventions: patients underwent sequencing for BMPR2 mutations; and 4) Type of outcome measure: the composite of death or lung transplantation. The exclusion criteria were as follows: 1) Duplicate reports describing the same cohort; 2) Certain publication types, such as conference abstracts, letters, comments, case reports and editorials; and 3) Studies not published in English.

\section{Data extraction and quality evaluation}

All studies retrieved by the search strategy were independently screened by 2 reviewers (XYG and TTZ). The initial prescreening was performed by reading the titles and abstracts to select relevant studies for further data extraction. Secondary selection was conducted by comprehensively reviewing the full text of all initially identified articles to determine whether the necessary information was reported. Disagreements were resolved through discussion or consultation with the 3rd reviewer $(\mathrm{YL})$. Data were extracted according to predetermined criteria, and a quality evaluation of the individual studies was then performed in accordance with the methodological standards proposed by McGinn and colleagues.

\section{Appraisal of the risk of bias of the included studies}

Two reviewers (XYG and TTZ) independently evaluated the risk of bias in accordance with the Cochrane Collaboration's "risk of publication bias" tool. Disagreements were resolved by consensus. Potential publication bias was evaluated by visually inspecting funnel plots and by analytical appraisal based on the Begg's adjusted-rank correlation test and Egger's linear regression test. According to the Begg or Egger methods for evaluating publication bias, a two-sided $P$ value of 0.10 or less was regarded as significant.

\section{Statistical analysis}

Statistical analyses were performed using Review Manager Version 5.3, Stata and SPSS Statistics. The chi-square statistic and independent-samples $\mathrm{T}$ tests were used to assess differences in the baseline characteristics of the two groups. The odds ratio (OR) was calculated and presented with the $95 \%$ confidence interval (CI) for summary estimates. Due to the heterogeneity among the included studies, appropriate statistical models were selected to ensure that the statistical data were estimated correctly. Cochran's chi-square test was performed, and the $\mathrm{I}^{2}$ statistic was determined to evaluate the heterogeneity among the included studies. Cochran's chi-square test was used 
to determine whether the observed difference may be due to chance alone. A low $P$ value (cut-off of 0.10 ) was taken to indicate the presence of significant heterogeneity among different studies. The $\mathrm{I}^{2}$ statistic describes the percentage of total variation across studies due to significant heterogeneity rather than random chance. An I ${ }^{2}$ statistic greater than $75 \%$ suggests considerable heterogeneity among the studies. Statistical significance was set at a $P$ value $<0.05$.

\section{Results}

The review process and characteristics of the included studies

Figure 1 shows the flowchart for the inclusion and exclusion of studies and patients. Literature search results and characteristics were initially obtained from 368 articles published in English, and 351 articles were obtained as full text. A total of 309 papers were removed after reviewing titles and abstracts were reviewed. Then, the full text of each of the remaining 42 articles was retrieved for further review to determine whether they met the predetermined criteria. Finally, 17 papers were identified and included in the present study [8-24].

The general characteristics of the included studies were shown in Table 1. The publication year ranged from 2006 to 2018. Based on the data in the 17 eligible trials, a total of $2198 \mathrm{PAH}$ patients were enrolled; among these, 681 (30.98\%) were BMPR2 mutation carriers and 1517 (69.02\%) were noncarriers. The sex ratio of female to male patients was $2.41 \quad(n=1554 / 644)$ in the total population, 2.04 $(n=457 / 224)$ among BMPR2 mutation carriers, and 2.61:1 $(n=1097 / 420)$ among noncarriers. IPAH and HPAH patients with BMPR2 mutations had more severe haemodynamic and functional parameters than those observed in noncarriers, and those with BMPR2 mutation were diagnosed at a younger age. (Table 2).

\section{Quality evaluation}

Table 3 showed that the included studies generally included patients with a variety of disease severities and who were generally selected in an unbiased fashion. In addition, the follow-up durations of the patients and issues relating to blinding were also acceptable. Therefore, both external and internal validity were adequate.

\section{Bias assessment and consistency test}

Visual inspection of a funnel plot (Fig. 2) showed that it had a symmetrical shape, and quantitative evaluation suggested there was no significant publication bias (Egger's test $[P=0.249]$, Begg's test $[P=0.232]$ ).

\section{BMPR2 mutations in male and female patients with IPAH or HPAH}

In a pooled analysis of all included patients with BMPR2 mutations, we observed very low heterogeneity $\left(\mathrm{I}^{2}: 10 \%\right)$, indicating that the variability among these studies was acceptable. Among all included PAH patients, $644 \mathrm{pa}-$ tients were male, including 224 patients $(34.78 \%)$ with BMPR2 mutations. Among the 1554 female patients, only 457 patients $(29.41 \%)$ had BMPR2 mutations. When the data were pooled across these studies, the results

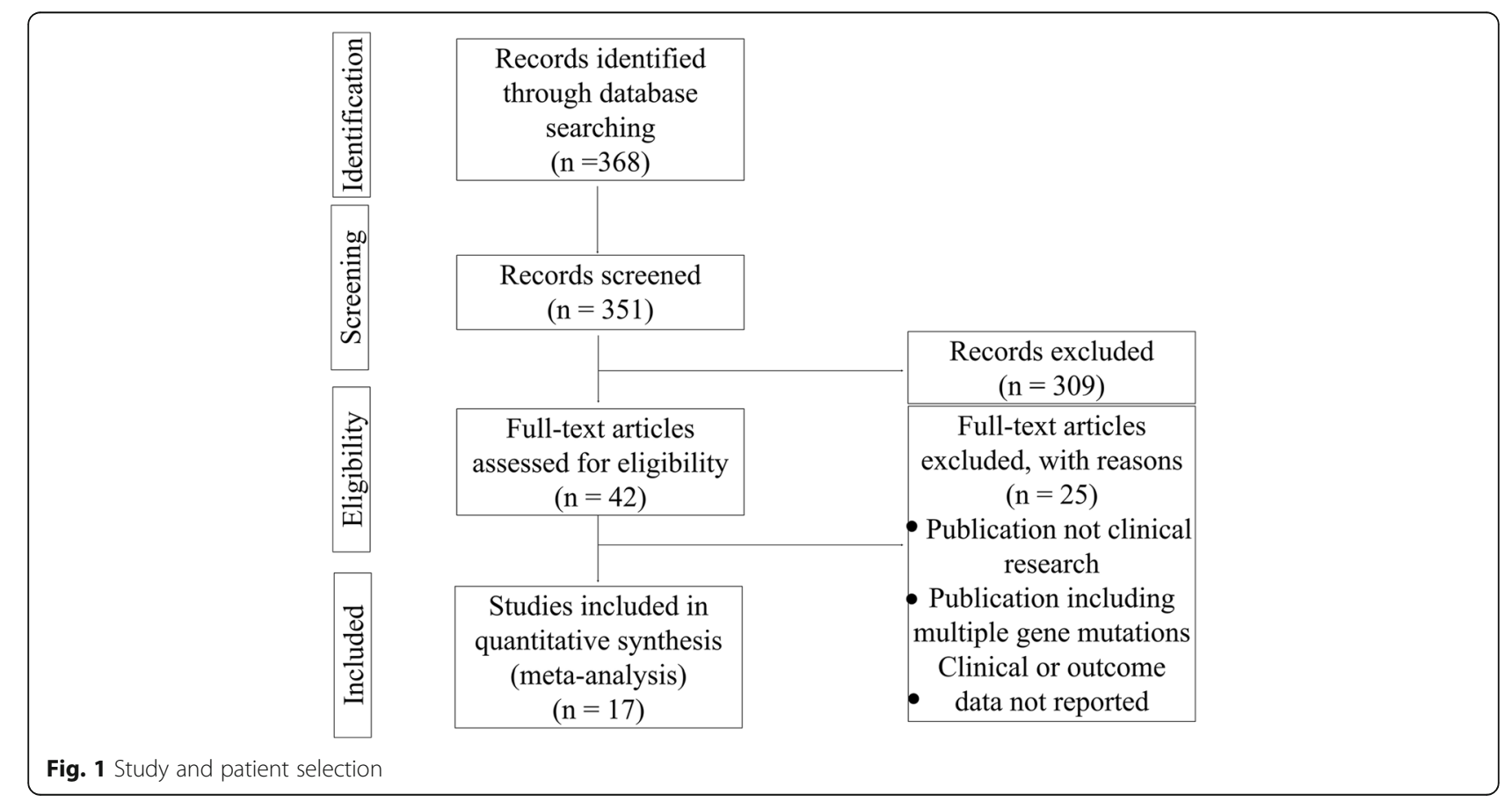


Table 1 General characteristics of the included studies

\begin{tabular}{|c|c|c|c|c|c|c|c|}
\hline Study ID & $\begin{array}{l}\text { PH types for data } \\
\text { extraction }\end{array}$ & Area & $\begin{array}{l}\text { Participants } \\
\text { (N) }\end{array}$ & $\begin{array}{l}\text { mutation /non- } \\
\text { mutation } \\
(\mathrm{N} / \mathrm{N})\end{array}$ & $\begin{array}{l}\text { Male/Female } \\
\text { (N/N) }\end{array}$ & Outcomes & Period \\
\hline Austin 2009 [8] & HPAH, IPAH & US & 147 & $106 / 41$ & $43 / 104$ & $\begin{array}{l}\text { death or lung } \\
\text { transplantation }\end{array}$ & $\begin{array}{l}\text { up to date as of } \\
2009.03\end{array}$ \\
\hline $\begin{array}{l}\text { Bruggen } 2016 \\
\text { [12] }\end{array}$ & HPAH, IPAH & Netherlands & 95 & $28 / 67$ & $23 / 72$ & $\begin{array}{l}\text { death or heart/lung } \\
\text { transplantaton }\end{array}$ & 1995.03 to 2014.10 \\
\hline Chida 2012 [20] & IPAH, HPAH & $\begin{array}{l}\text { Japan and } \\
\text { China }\end{array}$ & 54 & $18 / 36$ & $24 / 30$ & death & $\begin{array}{l}\text { 1995.01.01 to } \\
2011.03 .31\end{array}$ \\
\hline Elliott 2006 [21] & HPAH, IPAH & US & 67 & $27 / 40$ & $14 / 53$ & NA & 1994.07 - \\
\hline $\begin{array}{l}\text { Gamou } 2017 \\
\text { [14] }\end{array}$ & $\mathrm{HPAH}$ & Japan & 117 & $39 / 78$ & $31 / 86$ & NA & 2015 \\
\hline Ghigna 2016 [10] & HPAH, IPAH & French & 44 & $23 / 21$ & $16 / 28$ & lung transplantation & $2005-2014$ \\
\hline Girerd 2010 [9] & HPAH, IPAH & French & 382 & $115 / 267$ & $113 / 269$ & $\begin{array}{l}\text { death or lung } \\
\text { transplantation }\end{array}$ & $\begin{array}{l}2004.01 .01- \\
2010.04 .01\end{array}$ \\
\hline Isobe 2016 [18] & HPAH, IPAH & Japan & 59 & $23 / 36$ & $17 / 42$ & death & $2000.08-2015.10$ \\
\hline Kabata 2013 [13] & HPAH, IPAH & Japan & 49 & $18 / 31$ & $17 / 32$ & $\begin{array}{l}\text { death or lung } \\
\text { transplantation }\end{array}$ & 1999.10-2007.03 \\
\hline Liu 2012 [11] & HPAH, IPAH & China & 305 & $50 / 255$ & $87 / 218$ & death & $\begin{array}{l}2006.01 .01- \\
2010.08 .31\end{array}$ \\
\hline Mutlu 2016 [23] & IPAH, CHD-PAH & Turkish & 43 & $1 / 42$ & $21 / 22$ & NA & $2011-2012$ \\
\hline Navas 2016 [19] & HPAH, IPAH & Spain & 165 & $24 / 141$ & $41 / 124$ & $\begin{array}{l}\text { death or lung } \\
\text { transplantation }\end{array}$ & 2011.01-2015.05.01 \\
\hline Pfarr 2011 [17] & HPAH, IPAH & Germany & 228 & $49 / 179$ & $62 / 166$ & NA & 2006.01-2009.12 \\
\hline $\begin{array}{l}\text { Pousada } 2014 \\
\text { [22] }\end{array}$ & $\begin{array}{l}\text { IPAH and } \\
\text { Associated PAH }\end{array}$ & Spain & 41 & $9 / 32$ & $21 / 20$ & NA & 14 months \\
\hline $\begin{array}{l}\text { Rosenzweig } \\
2008 \text { [24] }\end{array}$ & HPAH, IPAH & US & 147 & $23 / 124$ & $49 / 98$ & NA & $1991-2005$ \\
\hline $\begin{array}{l}\text { Sztrymf } 2008 \\
{[15]}\end{array}$ & HPAH, IPAH & French & 233 & $68 / 165$ & $66 / 167$ & $\begin{array}{l}\text { death or lung } \\
\text { transplantation }\end{array}$ & 2004.01-2007.06 \\
\hline Yang 2018 [16] & HPAH, IPAH & China & 185 & $56 / 129$ & $48 / 137$ & NA & 2016-2017 \\
\hline
\end{tabular}

NA not available, $\mathrm{HAPH}$ heritable PAH, IPAH idiopathic PAH

Table 2 Hemodynamic and cardiac functional parameters according to the BMPR2 mutations of pulmonary hypertension

\begin{tabular}{lllll}
\hline Variables & Mutations & Non-mutations & MD/OR(95\%Cl) & $P$ value \\
\hline Age at diagnosis (yrs) & $35.12 \pm 12.79(556)$ & $40.17 \pm 16.25(1174)$ & $-3.70[-6.52,-0.87]$ & $<0.00001$ \\
6MWD (m) & $363.12 \pm 113.97(332)$ & $369.22 \pm 116.82(863)$ & $-14.81[-45.24,15.62]$ & 0.34 \\
mPAP (mmHg) & $61.21 \pm 12.73(570)$ & $56.37 \pm 14.08(1197)$ & $4.82[2.38,7.25]$ & 0.0001 \\
PVR (Wood units) & $18.65 \pm 8.69(557)$ & $15.11 \pm 7.8(1166)$ & $3.90[3.23,4.57]$ & $<0.000$ \\
CI (L/ml/m²) & $2.08 \pm 0.65(547)$ & $2.51 \pm 0.86(1156)$ & $-0.44[-0.63,-0.24]$ & $<0.000$ \\
RVP (mmHg) & $8.30 \pm 4.99(405)$ & $7.41 \pm 5.60,835(835)$ & $-0.32[-0.91,0.27]$ & 0.29 \\
NYHA III & $67.95 \%(312)$ & $70.22 \%(648)$ & $0.84[0.62,1.14]$ & 0.26 \\
NYHA IV & $11.54 \%(312)$ & $6.94 \%(648)$ & $1.71[1.07,2.72]$ & 0.02 \\
\hline GMWD
\end{tabular}

6MWD 6 min walk distance, mPAP mean PAP, PVR pulmonary vascular resistance, $C l$ cardiac index, RVP right ventricular pressure; these results are expressed as mean \pm SD. NYHA new york heart association functional classification, expressed as \% (patients number); $M D$ mean difference, $O R$ odd ratio, $95 \% \mathrm{Cl} 95 \%$ confidence interval 
Table 3 Quality Evaluation of the Individual Studies

\begin{tabular}{llllll}
\hline Study ID & Q1 & Q2 & Q3 & Q4 & Q5 \\
\hline Austin 2009 [8] & Yes & No & Yes & Yes & Yes \\
Bruggen 2016 [12] & Yes & No & Yes & Yes & Yes \\
Chida 2012 [20] & Yes & No & Yes & No & No \\
Elliott 2006 [21] & Yes & No & Yes & Yes & Yes \\
Gamou 2017 [14] & Yes & No & Yes & Yes & Yes \\
Ghigna 2016 [10] & Yes & No & Yes & Yes & Yes \\
Girerd 2010 [9] & Yes & No & Yes & Yes & Yes \\
Isobe 2016 [18] & Yes & No & Yes & Yes & Yes \\
Kabata 2013 [13] & Yes & No & Yes & Yes & Yes \\
Liu 2012 [11] & Yes & No & Yes & Yes & Yes \\
Mutlu 2016 [23] & Yes & No & Yes & Yes & Yes \\
Navas 2016 [19] & Yes & No & Yes & Yes & Yes \\
Pfarr 2011 [17] & Yes & No & Yes & Yes & Yes \\
Pousada 2014 [22] & Yes & No & Yes & Yes & Yes \\
Rosenzweig 2008 [24] & Yes & No & Yes & Yes & Yes \\
Sztrymf 2008 [15] & Yes & No & Yes & Yes & Yes \\
Yang 2018 [16] & Yes & No & Yes & Yes & Yes \\
\hline Q qustin: Q1 extrat valdys the patests &
\end{tabular}

Q question; Q1 (external validity): Did the patients represent a variety of disease severities?; Q2 (external validity): Did the included study exhibit bias? Q3 (internal validity): Was the follow-up percentage of all enrolled patients greater than 80\%?; Q4 (internal validity): Were the predictors to be evaluated blinded to the outcome events?; Q5 (internal validity): Were the outcome events blinded to the predictors?
(Fig. 3) showed that the male patients were significantly more likely than the female patients to have BMPR2 mutations $(\mathrm{OR}=1.30,95 \% \mathrm{CI}: 1.06 \sim 1.60, P=0.01)$.

\section{Mortality or lung transplantation rate}

Compared to non-carriers of BMPR2 mutation, carriers were associated with significantly higher mortality and lung transplantation rates $(\mathrm{OR}=1.90,95 \% \mathrm{CI}$ : 1.04 3.48, $P=0.04, \mathrm{I}^{2}=64 \%$ ) (Fig. 4a). Furthermore, we performed subgroup analyses among the studies according to gender to further explain the high heterogeneity observed among the trials. Similarly, the risk of death or transplantation was higher in PAH patients with BMPR2 mutations than in those without $(\mathrm{OR}=2.15,95 \% \mathrm{CI}$ : $\left.1.29 \sim 3.57, P=0.003, \mathrm{I}^{2}=24 \%\right)$. Moreover, this difference was significant only in male patients $(\mathrm{OR}=5.58,95 \% \mathrm{CI}$ : 2.16 14.39, $\left.P=0.0004, \mathrm{I}^{2}=0 \%\right)$ and not in female patients $\left(\mathrm{OR}=1.41,95 \% \mathrm{CI}: 0.75 \sim 2.67, P=0.29, \mathrm{I}^{2}=0 \%\right)$ (Fig. 4b).

\section{Discussion}

Of all BMPRs, BMPR2 is the most relevant to PAH. BMPR2 mutations were the first BMPR mutations to be discovered, and they are the most extensively studied mutations of those known to underlie HPAH. Transgenic mice with PAH expressing a dominant-negative BMPRII gene display aberrant pulmonary vascular cell phenotypes, including apoptosis of endothelial cells (ECs) and excessive proliferation of medial smooth muscle cells (SMCs) [25]. Metabolomic analysis demonstrated that BMPR2 mutations were associated with a wide range of metabolic abnormalities, including oxidative injury and insulin

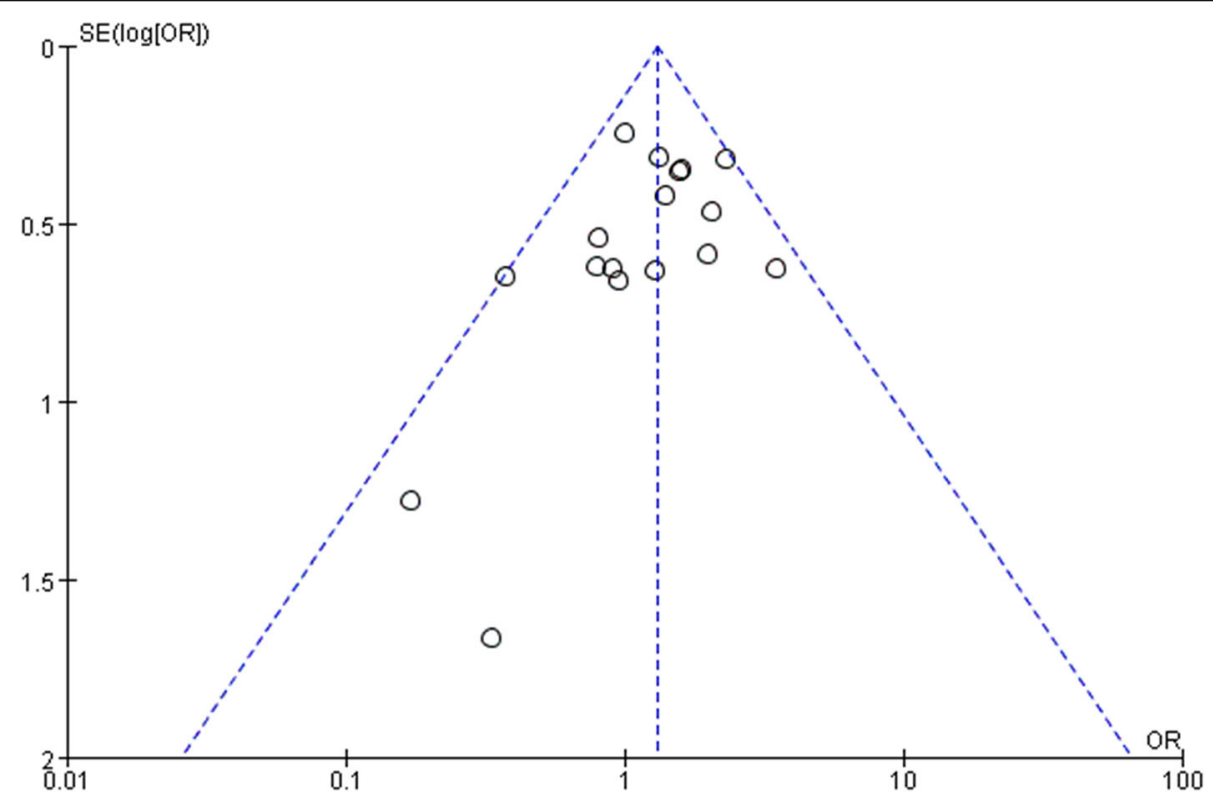

Fig. 2 Funnel plot showing all studies included in the bias analysis. logor, logarithm of odds ratio; s.e.: standard error 


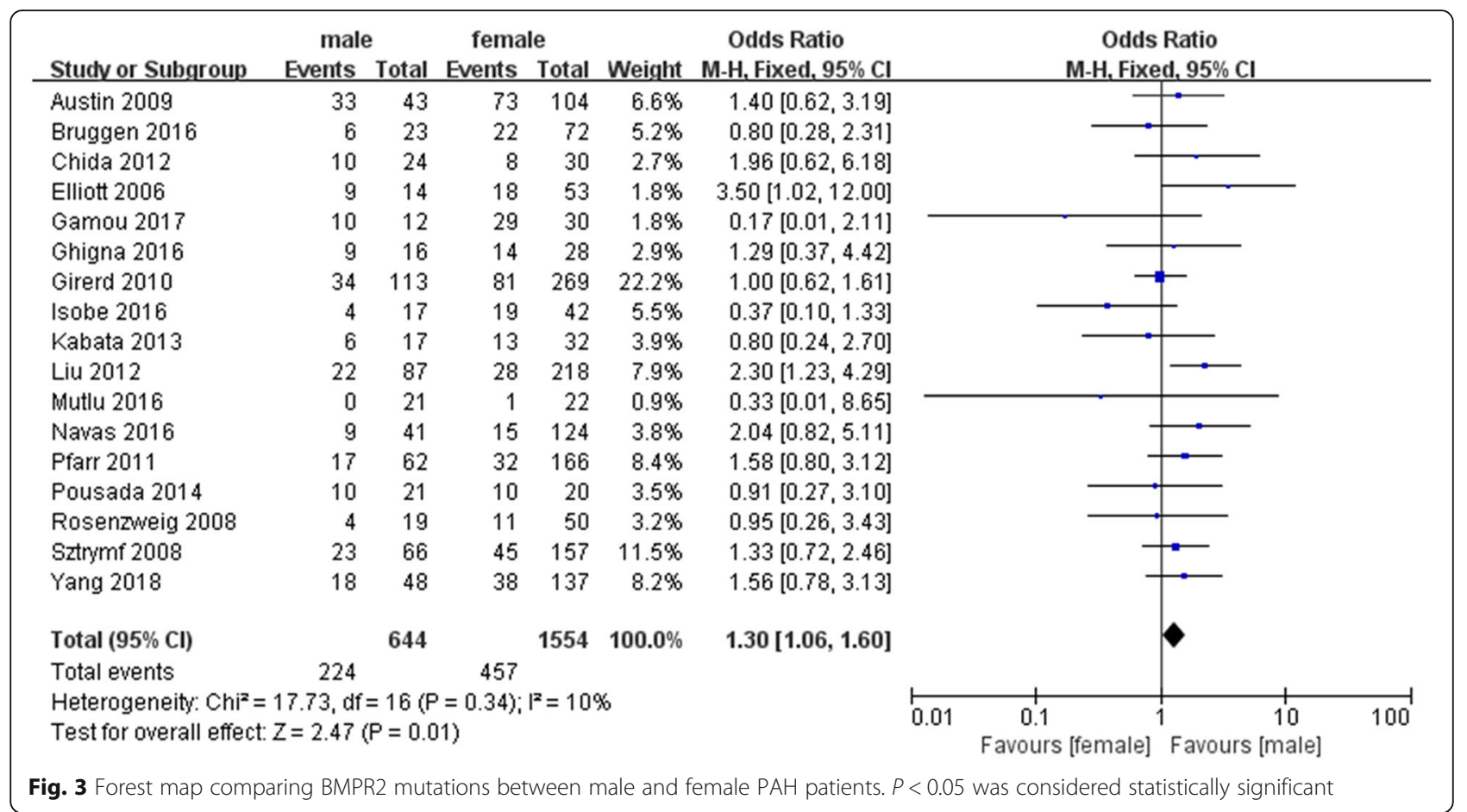

resistance in human pulmonary ECs. Furthermore, BMPR2 deficiency aggravates endothelial inflammatory responses, thereby contributing to adverse vascular remodeling [26]. Homozygous BMPR2(-/-) knockout mouse died in utero whereas heterozygous BMPR2(+/-) mice were viable but did not develop PAH spontaneously, even in the presence of a second hit such as hypoxia, mouse did not develop severe forms of PAH [27]. Given that BMP ligands and their receptors play important roles in disease progression, the regulation of this signal could function as a therapeutic target.

As mentioned earlier, there is a "sex paradox" in $\mathrm{PH}$ that it has long been known females have a higher susceptibility than males to $\mathrm{PAH}$, in which the most recent figures show that the female-to-male ratio is 4:1 [28]. In a large cohort of individuals with BMPR2 receptor mutations (including those with IPAH or HPAH or drug- and toxin-induced $\mathrm{PAH}$ ), approximately $70 \%$ of the patients were women [6]. Similar to previous studies, in our study, 457 of 681 PAH patients with BMPR2 mutations were women. Interestingly, among all female $\mathrm{PAH}$ patients, the proportion who had BMPR2 mutations was lower than the proportion of male $\mathrm{PH}$ patients with BMPR2 mutations out of all male PAH patients. Therefore, our and previous studies suggest that the pathogenesis of PAH may be more complicated in female than male PAH patients, and that the influence of BMPR2 mutations may be modified by additional unknown factors in female patients. A large and growing body of literatures have investigated the cross-talk between
BMPR2 and oestrogen signaling, which has been proposed as a critical mechanistic driver responsible for the female predominance of PAH. Austin ED ect. Showed that when oestrogen receptor alpha binds to the BMPR2 promoter, BMPR2 gene expression was reduced in females [29]. Mair and colleagues examined the expression of aromatase (a member of the cytochrome P-450 superfamily that synthesizes oestrogens via the aromatization of androgens) in human pulmonary artery smooth muscle cells (hPASMCs) and demonstrated that the level of aromatase was 12-fold higher in cells derived from postmenopausal women than in PASMCs derived from similarly aged men [30]. Furthermore, a large number of recent studies have focused on differences in hormone levels but have ignored the most fundamental difference between males and females: the sex chromosomes (XX versus XY). Yan and colleagues demonstrated that SRY on the $\mathrm{Y}$ chromosome binds to and positively regulates the BMPR2 promoter to reduce the prevalence of $\mathrm{PAH}$ in males [31]. Moreover, studies have demonstrated mitochondria also play an important role in PAH [32]. Does female mitochondria also be differ from male mitochondria? It's true! Mitochondria are passed to the offspring only from mother. Female mitochondria can respond to evolutionary pressure because they are passed on to the offspring. However, male mitochondria are not responsive to such pressures because they are locked in the host cell and cannot be passed on [33].

Studies have increasingly shown that inflammation plays an important role in $\mathrm{PAH}$ and the inflammatory 


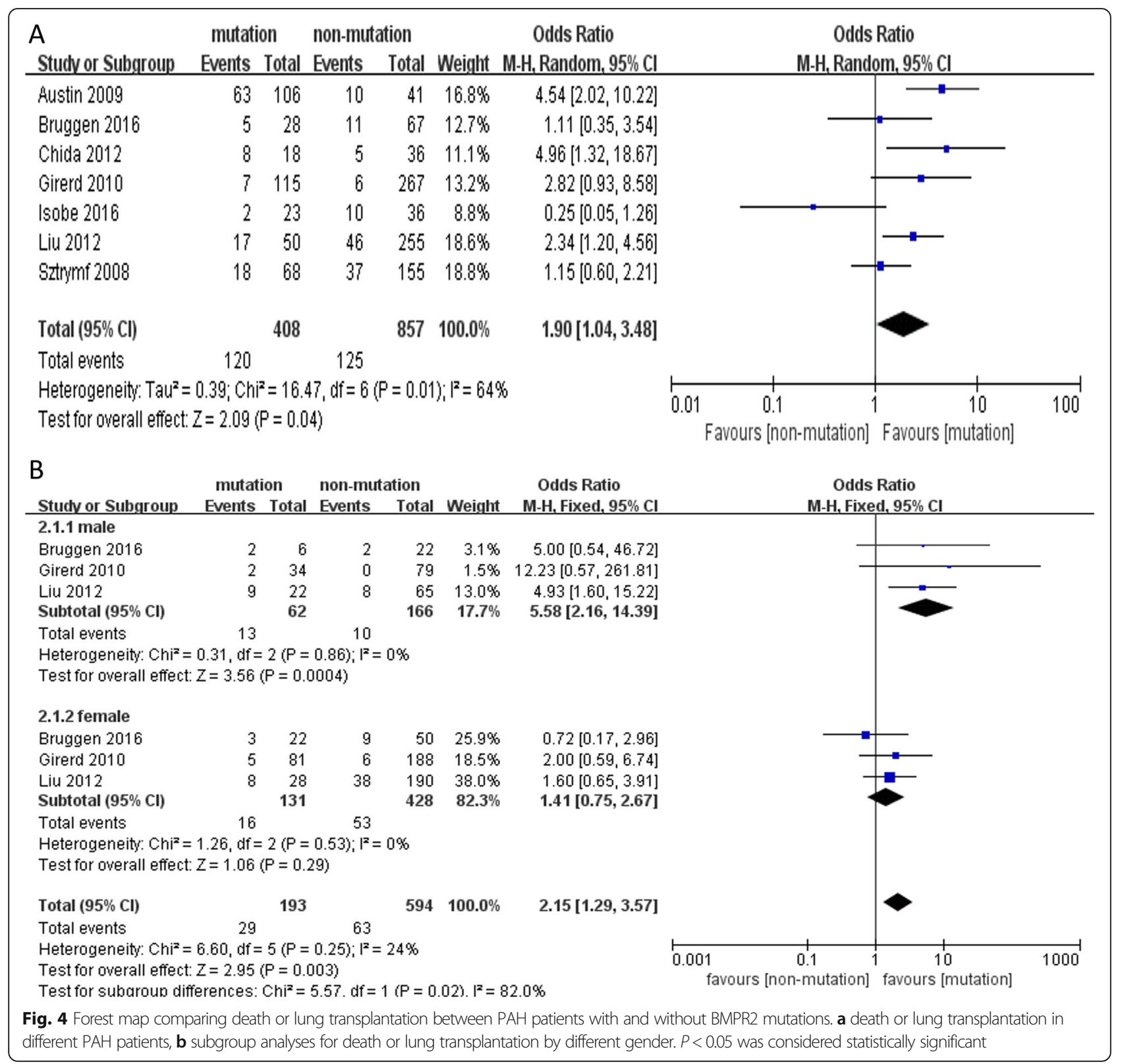

insult is also considered as a second hit potential triggering the pathogenesis of PAH [34]. The occurrence of $\mathrm{PAH}$ is related to various inflammatory factors, such as systemic inflammatory response, human immunodeficiency virus infection, autoimmune disease, etc. Evidence suggesting that inflammation is involved in the development of PAH was first presented in 1994. Tuder found that macrophages, $\mathrm{T}$ cells, $\mathrm{B}$ cells and other inflammatory cells infiltrate surrounding injured vessels in $\mathrm{PAH}$ patients with pulmonary plexiform lesions [35], and many studies have found significantly increased levels of inflammatory markers in the blood of PAH patients, including C-reactive protein (CRP), interleukins (IL, such as IL-1, IL-6, IL-8, and IL-10), monocyte chemotactic protein 1 (MCP-1), tumor necrosis factor- $\alpha$ (TNF- $\alpha$ ), and high mobility group box chromosomal protein 1 (HMGB1) [36]. Furthermore, differences in the immune system have been identified between men and women. Therefore, we predict that these sex-related differences in the immune system contribute to the $\mathrm{PH}$ "sex paradox". In addition to IPAH and HPAH, other World Health Organization (WHO) Group 1 PAH subgroups are also characterized by a female predominance [7], including connective tissue disease (CTD) and portopulmonary hypertension-associated PAH. CTD is more common in women than men, and when associated with $\mathrm{PAH}$, female/male ratios between 3.8:1 and 10:1 have been reported [10]. In systemic sclerosis, women are 
eight times more likely than men to be affected by PAH, and in systemic lupus erythematosus, women are 17 times more likely than men to be affected by PAH [8].

Our meta-analysis further confirmed a positive correlation between BMPR2 mutations and the severity of $\mathrm{PAH}$, which is consistent with previous studies [9], reporting that $\mathrm{PAH}$ patients carrying BMPR2 mutations have a higher mean pulmonary artery pressure and a lower cardiac index. Similar to the Evans study, we also found that in patients with $\mathrm{PAH}$, the risk of death or transplantation was higher among those with BMPR2 mutations than those without [6]. However, it is worth noting that when we conducted subgroup analyses according to gender to explore the sources of heterogeneity, we found that the difference was significant only in male patients but not in female patients. To explain this finding, we first focused on differences in sex hormones between males and females. Similar to the "sex paradox", there are also "oestrogen paradoxes" in PAH [7]. At low doses, oestrogen acts as a pro-oxidant, whereas at higher doses, it acts to suppress oxidative stress. In addition to its dose-effect, studies have demonstrated that some oestrogen metabolites (such as $17-\beta$ oestradiol and 2$\mathrm{OH}$-estradiol) can also promote antiproliferative and proapoptotic signals, inhibit oxidative stress and collagen deposition, and protect right ventricular function in $\mathrm{PAH}$, while other metabolites (such as $16-\alpha-\mathrm{OH}-$ oestradiol) have the opposite effects [28]. The effects of key enzymes in the lungs (such as CYP1B1 and catechol-O-methyl-transferase (COMT)) have also been explored. CYP1B1 is the most efficient oestradiol hydroxylase, and the $2-\mathrm{OH}$-estradiol $/ 16 \alpha-\mathrm{OH}$-estrone ratio is an indicator of CYP1B1 activity [37]. In the presence of COMT, 2-Methoxy-estradiol is rapidly formed. The imbalance of oestrogen metabolites has been proposed to be the basis of the differential effects of oestrogens on male versus female pulmonary vascular cells [38]. As mentioned earlier, in addition to hormonal factors, there are also differences in the immune system between men and women. Some studies have demonstrated that Tregs are more critical for the maintenance of immune homeostasis in females than in males. Treg cells can maintain immune homeostasis and suppress inflammatory responses by regulating the function of effector $\mathrm{T}$ cells. Under physiological conditions, Th17 and Treg are in a dynamic equilibrium. In PAH, the balance of Th17 and Treg is broken, and Th17 cells, which have proinflammatory effects, are increased, and the activation of Treg cells, which exert anti-inflammatory protective effects, is reduced [39]. Osman and colleagues found that Tregs suppressed inflammation, immune dysregulation and vascular remodeling in females and that they thereby exert a protective effect in PAH models [33]. Moreover, metabolic theory suggests that vascular cell mitochondria can induce a proliferative, antiapoptotic phenotype and the inflammasome, thus initiating a cascade of events that increases the levels of many inflammatory cytokines described in PAH [40]. Hence, female mitochondria may be different from male mitochondria. Oocytes cell mitochondria have different ultrastructures, slower metabolic activity and lower levels of ROS production than those observed in sperm cell mitochondria. Importantly, mitochondria can strongly regulate the functions of $\mathrm{T}$ cells. For example, mitochondrial suppression of oxidative phosphorylation is a necessary step preceding $\mathrm{T}$ cell activation [41].

Our results also indicate that screening for BMPRR2 mutations is more important in men than in women. First, we presented evidence from 17 published clinical trials in this review and suggested that among $2198 \mathrm{PAH}$ patients, BMPR2 mutations accounted for a higher proportion of all factors leading to $\mathrm{PAH}$ in men than women. Second, the PAH patients with BMPR2 mutations had more severe haemodynamic and functional parameters than noncarriers, and the carriers were diagnosed at younger ages. The risk of death or transplantation in PAH patients with BMPR2 mutations was higher than that in those without such mutations. The third and last, the difference was significant only in male patients. Therefore, treatment of aberrant BMPR2 expression may exert better effects in male IPAH and HPAH patients than in female patients. This study also has some shortcomings. We found that male PAH patients are more likely than female patients to have BMPR2 mutations, but whether this difference is related to the severity of male PAH has not been further explored. The main reason is that many end points of the included clinical studies were only systematically compared with regard to the presence or absence of BMPR2 mutations, and no stratified analysis of males and females has been performed. We recommend a previously completed or ongoing trial or registration of $\mathrm{PAH}$ should be analyzed in a gender subgroup analysis of patients with BMPR2 mutations to determine whether gender differences in BMPR2 mutations are associated with gender differences in disease severity among this patient population. Moreover, some heterogeneity was observed in the mortality or lung transplantation rates among the trials. In Isobe's study, we observed that the overall results were consistent with other studies. The all-cause mortality was similar between the BMPR2 carriers and non-carriers, but in contrast to the other included studies, this study found that the all-cause mortality was higher among the BMPR2 non-carriers. The reasons may be summarized as follows: the population explored in this study were treated with $\mathrm{PGI}_{2}$, while the other studies did not involve treatment, and $13.6 \%$ of the entire cohort in this study had familial pulmonary 
hypertension, which is twice the $6 \%$ reported in the U.S. registry conducted in the 1980s. Thus, we cannot deny the possibility that ethnicity contributes to the impact of BMPR2 mutations on the outcome. Indeed, the heterogeneity was greatly reduced after eliminating Isobe's study (from 64 to $49 \%$, data not shown). Thus, a worldwide, large-scaled prospective study should be performed in the near future to elucidate the differences in among response to the currently available combination therapies between for BMPR2. What's more, there are studies have reported that gender-based differences in PAH prevalence appear to be diminished among older patients [42]. Therefore, an another important modifier of the relationship between gender and outcomes in $\mathrm{PAH}$ may be is age, which suggests that temporal changes in the hormonal milieu may impact disease risk and severity throughout the lifespan [43]. Just as we discussed before, race/ethnicity may also modify the relationship between sex and PAH. So, we probably group it more finely, such as by region, age, etc., to further explain the high heterogeneity.

\section{Conclusion}

In this review, we presented evidence from 17 published clinical trials and suggested that among $2198 \mathrm{HPAH}$ and IPAH patients, BMPR2 mutations accounted for a higher proportion out of all factors that led to $\mathrm{PAH}$ in men than in women. Moreover, IPAH and HPAH patients with BMPR2 mutations had more severe haemodynamic and functional parameters than noncarriers, and those carriers were diagnosed at younger ages. The higher risk of death or transplantation was higher in PAH patients with BMPR2 mutations than in those without. Furthermore, the difference was significant only in male patients. Therefore, the restoration of BMPR2 expression and regulation of the BMPR2 signalling pathway are expected to represent an effective method for the treatment of PAH, and given the findings of our metaanalysis results, we speculate that the therapeutic effects of restoring BMPR2 expression may be better in male than that in female PAH patients.

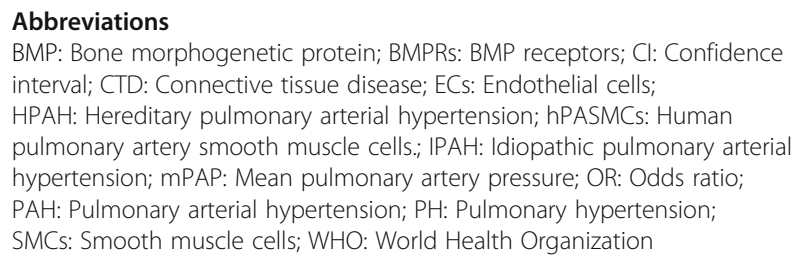

\section{Acknowledgments}

We really appreciate the efforts of all the researchers whose articles were included in this study.

\section{Authors' contributions}

$Y W, T Z$ and $X G$ finished the study design. $Y L$ and $Y W$ were consulted about clinical issues. $X G, T Z$ and $W Z$ contributed to the original draft. $Y L$ and $X Z$ were responsible for the revision of the draft. XG and WZ contributed equally to this article. All of the authors approved the final work prior to submission.

\section{Funding}

This work was supported by grants from the National Natural Science Foundation of China (No. 81960015 to WF. Zhang, No. 81800051 TT. Zhu) and the Youth Science Foundation from the Science and Technology Department of Jiangxi province (No. 20171 BAB215002 to WF. Zhang, No. 20171 BAB215040 to XY. Zhang, No. 20161BAB215251 to YL. Wang).

Availability of data and materials

Data are available from the authors upon request.

Ethics approval and consent to participate

Not applicable.

\section{Competing interests}

The authors declare that they have no competing interests.

\section{Author details}

'Department of Pharmacy, The Second Affiliated Hospital of Nanchang University, Nanchang 330006, China. ${ }^{2}$ Teaching and Research Office of Clinical Pharmacology, College of Pharmacy, Xinxiang Medical University, Xinxiang 453003, China.

Received: 13 September 2019 Accepted: 29 January 2020

Published online: 06 February 2020

\section{References}

1. Ezekian JE, Hill KD. Management of pulmonary arterial hypertension in the pediatric patient. Curr Cardiol Rep. 2019;21:162.

2. Coons JC, Pogue K, Kolodziej AR, Hirsch GA, George MP. Pulmonary arterial hypertension: a Pharmacotherapeutic update. Curr Cardiol Rep. 2019;21:141.

3. Liu D, Morrell NW. Genetics and the molecular pathogenesis of pulmonary arterial hypertension. Curr Hypertens Rep. 2013:15:632-7.

4. Hautefort A, Mendes-Ferreira P, Sabourin J, Manaud G, Bertero T, RuckerMartin C, Riou M, Adão R, Manoury B, et al. Bmpr2 mutant rats develop pulmonary and cardiac characteristics of pulmonary arterial hypertension. Circulation. 2019:139:932-48.

5. Newman JH, Trembath RC, Morse JA, Grunig E, Loyd JE, Adnot S, Coccolo F, Ventura C, Phillips JA, Knowles JA, Janssen B, Eickelberg O, Eddahibi S, Herve P, Nichols WC, Elliott G. Genetic basis of pulmonary arterial hypertension:current understanding and future directions. J Am Coll Cardiol. 2004;43:S33-9.

6. Evans JD, Girerd B, Montani D, Wang XJ, Galiè N, Austin ED, Elliott G, Asano K, Grünig E, et al. BMPR2 mutations and survival in pulmonary arterial hypertension: an individual participant data meta-analysis. Lancet Respir Med. 2016:4:129-37.

7. Foderaro A, Ventetuolo CE. Pulmonary arterial hypertension and the sex hormone paradox. Curr Hypertens Rep. 2016;18:84.

8. Austin ED, Phillips JA, Cogan JD, Hamid R, Yu C, Stanton KC, Phillips CA, Wheeler LA, Robbins IM, Newman JH, Loyd JE. Truncating and missense BMPR2 mutations differentially affect the severity of heritable pulmonary arterial hypertension. Respir Res. 2009;10:87.

9. Girerd B, Montani D, Eyries M, Yaici A, Sztrymf B, Coulet F, Sitbon O, Simonneau G, Soubrier F, Humbert M. Absence of influence of gender and BMPR2 mutation type on clinical phenotypes of pulmonary arterial hypertension. Respir Res. 2010;11:73.

10. Ghigna MR, Guignabert C, Montani D, Girerd B, Jaïs X, Savale L, Hervé $P$, Thomas de Montpréville $V$, Mercier O, et al. BMPR2 mutation status influences bronchial vascular changes in pulmonary arterial hypertension. Eur Respir J. 2016:48:1668-81.

11. Liu D, Wu WH, Mao YM, Yuan P, Zhang R, Ju FL, Jing ZC. BMPR2 mutations influence phenotype more obviously in male patients with pulmonary arterial hypertension. Circ Cardiovasc Genet. 2012;5:511-8.

12. van der Bruggen $C E$, Happé $C M$, Dorfmüller P, Trip P, Spruijt OA, Rol N, Hoevenaars FP, Houweling AC, Girerd B, et al. Bone morphogenetic protein receptor type 2 mutation in pulmonary arterial hypertension: a view on the right ventricle. Circulation. 2016;133:1747-60. 
13. Kabata H, Satoh T, Kataoka M, Tamura Y, Ono T, Yamamoto M. Huqun Hagiwara K, Fukuda K, Betsuyaku T, Asano K. bone morphogenetic protein receptor type 2 mutations, clinical phenotypes and outcomes of Japanese patients with sporadic or familial pulmonary hypertension. Respirology. 2013;18:1076-82

14. Gamou S, Kataoka M, Aimi Y, Chiba T, Momose Y, Isobe S, Hirayama T, Yoshino H. Fukuda K2, Satoh T. genetics in pulmonary arterial hypertension in a large homogeneous Japanese population. Clin Genet. 2018;94:70-80.

15. Sztrymf B, Coulet F, Girerd B, Yaici A, Jais X, Sitbon O, Montani D, Souza R, Simonneau G, Soubrier F, Humbert M. Clinical outcomes of pulmonary arterial hypertension in carriers of BMPR2 mutation. Am J Respir Crit Care Med. 2008;177:1377-83.

16. Yang H, Zeng Q, Ma Y, Liu B, Chen Q, Li W, Xiong C, Zhou Z. Genetic analyses in a cohort of 191 pulmonary arterial hypertension patients. Respir Res. 2018;19:87.

17. Pfarr N, Szamalek-Hoegel J, Fischer C, Hinderhofer K, Nagel C, Ehlken N, Tiede H, Olschewski H, Reichenberger F, Ghofrani AH, Seeger W, Grünig E. Hemodynamic and clinical onset in patients with hereditary pulmonary arterial hypertension and BMPR2 mutations. Respir Res. 2011;12:99.

18. Isobe S, Kataoka M, Aimi Y, Gamou S, Satoh T, Fukuda K. Improved survival of patients with pulmonary arterial hypertension with BMPR2 mutations in the last decade. Am J Respir Crit Care Med. 2016;193:1310-4.

19. Navas P, Tenorio J, Quezada CA, Barrios E, Gordo G, Arias P, López Meseguer M, Santos-Lozano A, Palomino Doza J, Lapunzina P, Escribano SP. Molecular analysis of BMPR2, TBX4, and KCNK3 and genotype-phenotype correlations in spanish patients and families with idiopathic and hereditary pulmonary arterial hypertension. Rev Esp Cardiol (Engl Ed). 2016;69:1011-9.

20. Chida A, Shintani M, Yagi H, Fujiwara M, Kojima Y, Sato H, Imamura S, Yokozawa M, Onodera N, et al. Outcomes of childhood pulmonary arterial hypertension in BMPR2 and ALK1 mutation carriers. Am J Cardiol. 2012;110:586-93.

21. Elliott CG, Glissmeyer EW, Havlena GT, Carlquist J, McKinney JT, Rich S, McGoon MD, Scholand MB, Kim M, Jensen RL, Schmidt JW, Ward K. Relationship of BMPR2 mutations to Vasoreactivity in pulmonary arterial hypertension. Circulation. 2006;113:2509-15.

22. Pousada G, Baloira A, Vilariño C, et al. Novel mutations in BMPR2, ACVR1 and KCNA5 genes and hemodynamic parameters in patients with pulmonary arterial hypertension. PLoS One. 2014;9:e100261.

23. Mutlu Z, Kayıkçıŏlu M, Nalbantgil S, Vuran Ö, Kemal H, Moğulkoç N, Ertürk B, Onay $H$, Eroğlu Z, Kültürsay H. Sequencing of mutations in the serine/threonine kinase domain of the bone morphogenetic protein receptor type 2 gene causing pulmonary arterial hypertension. Anatol J Cardiol. 2016;16:491-6.

24. Rosenzweig EB, Morse JH, Knowles JA, Chada KK, Khan AM, Roberts KE, McElroy JJ, Juskiw NK, Mallory NC, Rich S, Diamond B, Barst RJ. Clinical implications of determining BMPR2 mutation status in a large cohort of children and adults with pulmonary arterial hypertension. J Heart Lung Transplant. 2008;27:668-74.

25. Orriols M, Gomez-Puerto MC, Ten Dijke P. BMP type II receptor as a therapeutic target in pulmonary arterial hypertension. Cell Mol Life Sci. 2017;74:2979-95.

26. Soon E, Crosby A, Southwood M, Yang P, Tajsic T, Toshner M, Appleby S, Shanahan CM, Bloch KD, Pepke-Zaba J, Upton P, Morrell NW. Bone morphogenetic protein receptor type II deficiency and increased inflammatory cytokine production. A gateway to pulmonary arterial hypertension. Am J Respir Crit Care Med. 2015;192:859-72.

27. Maarman G, Lecour S, Butrous G, Thienemann F, Sliwa K. A comprehensive review: the evolution of animal models in pulmonary hypertension research; are we there yet? Pulm Circ. 2013;3:739-56.

28. Docherty CK, Harvey KY, Mair KM, , Griffin S, Denver N, MacLean MR. The role of sex in the pathophysiology of pulmonary hypertension. Adv Exp Med Biol 2018;1065:511-528.

29. Austin ED, Hamid R, Hemnes AR, Loyd JE, Blackwell T, Yu C, Phillips lii JA, Gaddipati R, Gladson S, Gu E, West J, Lane KB. BMPR2 expression is suppressed by signaling through the estrogen receptor. Biol Sex Differ. 2012;3:6.

30. Mair KM, Wright AF, Duggan N, Rowlands DJ, Hussey MJ, Roberts S, Fullerton J, Nilsen M, Loughlin L, Thomas M, MacLean MR. Sex-dependent influence of endogenous estrogen in pulmonary hypertension. Am J Respir Crit Care Med. 2014;190:456-67.

31. Yan L, Cogan JD, Hedges LK, Nunley B, Hamid R, Austin ED. The $Y$ chromosome regulates BMPR2 expression via SRY: a possible reason "why" fewer males develop pulmonary arterial hypertension. Am J Respir Crit Care Med. 2018;198:1581-3.
32. Marshall JD, Bazan I, Zhang Y, Fares WH, Lee PJ. Mitochondrial dysfunction and pulmonary hypertension: cause, effect, or both. Am J Phys Lung Cell Mol Phys. 2018;314:L782-96.

33. Osman MS, Michelakis ED. Immunity comes to play in the "sex paradox" of pulmonary arterial hypertension. Circ Res. 2018;122:1635-7.

34. Tielemans B, Delcroix M, Belge C, Quarck R. TGF $\beta$ and BMPRII signalling pathways in the pathogenesis of pulmonary arterial hypertension. Drug Discov Today. 2019;24:703-16.

35. Price LC, Wort SJ, Perros F, Dorfmüller P, Huertas A, Montani D, CohenKaminsky $S$, Humbert M. Inflammation in pulmonary arterial hypertension. Chest. 2012;141:210-21.

36. Pezzuto B, Badagliacca R, Poscia R, Ghio S, D'Alto M, Vitulo P, Mulè M, Albera C, Volterrani M, Fedele F, Vizza CD. Circulating biomarkers in pulmonary arterial hypertension: update and future direction. J Heart Lung Transplant. 2015:34:282-305.

37. Lee AJ, Cai MX, Thomas PE, Conney AH, Zhu BT. Characterization of the oxidative metabolites of 17beta-estradiol and estrone formed by 15 selectively expressed human cytochrome p450 isoforms. Endocrinology. 2003;144:3382-98

38. Paulin R, Michelakis ED. The estrogen puzzle in pulmonary arterial hypertension. Circulation. 2012;126:1016-9.

39. Maston LD, Jones DT, Giermakowska W, Howard TA, Cannon JL, Wang W Wei Y, Xuan W, Resta TC, Gonzalez Bosc LV. Central role of T helper 17 cells in chronic hypoxia-induced pulmonary hypertension. Am J Phys Lung Cell Mol Phys. 2017;312:L609-24.

40. Sutendra G, Michelakis ED. The metabolic basis of pulmonary arterial hypertension. Cell Metab. 2014;19:558-73.

41. Almeida L, Lochner M, Berod L, Sparwasser T. Metabolic pathways in T cell activation and lineage differentiation. Semin Immunol. 2016;28:514-24.

42. Ventetuolo CE, Praestgaard A, Palevsky HI, Klinger JR, Halpern SD, Kawut SM. Sex and haemodynamics in pulmonary arterial hypertension. Eur Respir J. 2014;43:523-30.

43. Hester J, Ventetuolo C, Lahm T. Sex, gender, and sex hormones in pulmonary hypertension and right ventricular failure. Compr Physiol. 2019; 10:125-70.

\section{Publisher's Note}

Springer Nature remains neutral with regard to jurisdictional claims in published maps and institutional affiliations.
Ready to submit your research? Choose BMC and benefit from:

- fast, convenient online submission

- thorough peer review by experienced researchers in your field

- rapid publication on acceptance

- support for research data, including large and complex data types

- gold Open Access which fosters wider collaboration and increased citations

- maximum visibility for your research: over $100 \mathrm{M}$ website views per year

At BMC, research is always in progress.

Learn more biomedcentral.com/submissions 